\title{
Zinc distribution within breast cancer tissue of different intrinsic subtypes
}

\author{
Peter Rusch ${ }^{2}$ - $\cdot$ Alfred V. Hirner ${ }^{1} \cdot$ Oliver Schmitz $^{1} \cdot$ Rainer Kimmig $^{2} \cdot$ Oliver Hoffmann $^{2} \cdot$ Maxim Diel $^{1}$
}

Received: 14 May 2020 / Accepted: 4 September 2020 / Published online: 15 September 2020

(c) The Author(s) 2020

\begin{abstract}
Purpose To show feasibility of laser ablation inductively coupled mass spectrometry (LA-ICPMS) for analysis of zinc content and concentration in breast cancer tissue and to correlate this with validated prognostic and predictive markers, i.e. histological grading and expression of steroid receptors (estrogen receptor, ER; progesterone receptor, PR) and human epidermal growth-factor receptor 2 (Her2).

Methods 28 samples of human invasive ductal breast cancer tissue were subclassified into groups of four different intrinsic subtypes according to the expression of ER, PR and Her2 by immunohistological staining and then analyzed for zinc content and distribution by LA-ICPMS applying a calibration technique based on spiked polyacrylamide gels. A correlation of zinc concentration with histological grading and molecular subtypes was analyzed.

Results Consistent with results of a pilot-study LA-ICPMS was feasible to show zinc accumulation in cancerous tissue, even more adjacent healthy stroma was with proportional increase of zinc. Zinc levels were most elevated in triple-positive (TPBC) and in triple-negative (TNB) breast cancers.

Conclusion LA-ICPMS was feasible to confirm a connection between zinc and grade of malignancy; furthermore, focusing on a correlation of zinc and intrinsic breast cancer subtypes, LA-ICPMS depicted an upwards trend of zinc for "high-riskcancers" with highest levels in Her2-positive and in triple-negative (TNBC) disease. The currently uncommon alliance of clinicians and analytical chemists in basic research is most promising to exploit the full potential of diagnostic accuracy in the efforts to solve the enigma of breast cancer initiation and course of disease.
\end{abstract}

Keywords Breast cancer · Zinc · Laser ablation inductively coupled mass spectrometry (LA-ICPMS) - Steroid receptor · Human epidermal growth factor receptor $2 \cdot$ Biomarker

Peter Rusch

Peter.Rusch@uk-essen.de

Alfred V. Hirner

alfred.hirner@uni-due.de

Oliver Schmitz

oliver.schmitz@uni-due.de

Rainer Kimmig

Rainer.Kimmig@uk-essen.de

Oliver Hoffmann

Oliver.Hoffmann@uk-essen.de

Maxim Diel

maxim.diel@gmail.com

1 Applied Analytical Chemistry, Department of Chemistry, University of Duisburg-Essen, Universitätsstraße 5-7, 45141 Essen, Germany

2 Department of Gynecology and Obstetrics, School of Medicine, University of Duisburg-Essen, Hufelandstr. 55, 45122 Essen, Germany

\section{Introduction}

Breast cancer is the most common cancer in women worldwide and still, it is the fifth most common reason for death from cancer in women. In the United States (US), lifetime risk for invasive breast cancer is one in eight [1].

With a peak incidence in postmenopause, an increasing number of premenopausal very young women is affected. About $5-10 \%$ of breast cancer is related to gene mutations with a focus on BRCA1- and 2-mutations [2]. A heterogeneous complex of diseases exists with distinct biological features that lead to different treatment options and clinical outcomes.

Still clinical markers commonly used to classify breast cancer are tumor size, lymph node involvement, histological grade, expression of steroid receptors (estrogen receptors $[\mathrm{ER}] /$ progesterone receptors [PR]) and human epidermal 
growth factor receptor 2 (Her2), but recent studies have focused on more detailed biological characteristics to improve patient risk stratification and the benefit to sideeffect ratio from a specific treatment modality [3-5].

In this context, Perou [6] and Sorlie [7] were the first to analyze gene expression patterns in breast cancer and to investigate their clinical relevance. The result was a molecular subclassification of different subtypes of breast cancer characterized by clusters with expression of distinct genes coding for steroid receptors, Her2 protein and the proliferation marker Ki57 [8]. This was only the prologue for an even more sophisticated insight into the complex pathway of tumor signaling.

Association of these "molecular" subtypes with course of disease and outcome [9] revealed, that distinct breast cancers have their own unique "intrinsic" molecular portrait. It was shown that Her2-positive and triple-negative breast cancers (TNBC) generally had the poorest survival [10]. While the introduction of Her2-targeted therapies dramatically improved outcomes for the Her2-positive subgroup $[11,12]$, TNBC is still with unfavorable prognosis due to the absence of a respective target receptor and is merely treated by chemotherapy.

High-throughput methods for gene expression and subsequent categorization of different breast cancer subtypes is now established in commercial tests already [13-15]. Interestingly, despite differences in candidate genes in each of the assays most of them quite reliably predict the biology (metastases-free-/overall survival) of the tumor tested. While these tests focus on certain but different mutations in drivergenes they all show more or less feasibility as prognostic and/or predictive tool for decision making. In fact, it is possible that - unless the great benefit of molecular testing - the link to solve the enigma between the genetic portrait and the biological behavior of breast cancer is still missing.

The trace metal zinc $(\mathrm{Zn})$ is known to be involved in multiple cellular processes [16]. Being a cofactor for more than 300 enzymes (e.g. all RNA-polymerases are zinc metalloenzymes) zinc contributes to cellular signaling, proliferation, homeostasis, immunofunction, oxidative stress, apoptosis and aging $[17,18]$. Zinc-associated proteins are metallothioneins, zinc transporters (esp. ZnT2, and Zip 6, 7, 10), p53 tumor suppressor and matrix metalloproteases-factors all being involved in carcinogenesis and tumor progression. This may be true particularly for breast cancer where zinc is at the interface of checkpoints of cancer initiation, promotion and progression while influencing gene expression at the level of the cell nucleus by stabilizing structure and thus regulating transcription factors, e.g. nuclear factor-kappa $B$ (NF-kB) [19-23].

Intracellular zinc is important for rapidly dividing cancer cells, thus zinc homeostasis in normal cells being dysregulated in cancer cells [21]. Zinc levels in cancerous and in non-cancerous tissues were analyzed in many studies since the $70 \mathrm{~s}$ [24-29]. Elevated zinc levels were found in cancers of the breast, the colorectum, and of head and neck, while cancers of other origin (i.e. prostate, liver, stomach) show an inverse correlation [30]. Only one author describes decreased zinc levels in breast cancer [31].

With regard to the relevance of cancer-initiation, Cui observed a correlation between high levels of zinc in breast tissue and the onset of carcinogenesis [32]. Zinc levels were found to be higher in estrogen-receptor (ER)-positive breast cancers [33], while distinctive "subtype"-specific dysregulations of zinc-homeostasis were described [22]. Tamoxifenresistant breast cancer cells showed with increased intracellular zinc [34]. Again, authors proposed the role of the zinc-transporter ZIP7 in the control of intracellular zinc homeostasis [35].

While the optimal immunostimulatory dose of zinc has not yet been determined, research focuses also on dietary effects and on suitable chemotherapies. In this context, there is evolving evidence for zinc not only as a (diagnostic) biomarker but as a therapeutic agent, too [36-38].

Besides well-established histopathological analyses, different analytical methods exist for the detection and diagnosis of cancer. Synchrotron micro-X-Rax-Fluorescence ( $\mu$-SXRF) or Laser-Ablation-Inductively Coupled Mass Spectrometry (LA-ICPMS) are spacial resolving analytical methods providing a kind of "heatmap" of distribution and concentration of distinct trace elements in a tissue sample. These analytical techniques have shown equivalence in differentiating between cancer cell clusters and adjacent stroma. Analysis was feasible on a single tissue section and was not dependent on paired samples (see Fig. 1).

Discrepancy of zinc level and distribution between normal and cancerous tissue can range widely - from very few to more than $80 \mathrm{ppm}$. This may correlate with histologic grading and expression of steroid-receptor-status [33].

A feasibility study of LA-ICPMS for zinc analysis in breast cancer showed correlations of zinc amount, concentration, and distribution with histopathological phenotypic grade $(\mathrm{G})$ of malignancy in breast cancer. Zinc levels roughly doubled from G1 to G3 cancer. Nonetheless, this was shown on a small set of nine samples only [39].

This present study was intended as a follow-up study according to Riesop [39], thus using LA-ICPMS on a bigger set of 28 human breast cancer samples. This time zinc content and concentration of LA-ICPMS-analysis were correlated with "molecular/intrinsic" subtypes according to the immunohistochemical expression of steroid (ER/PR) and Her2 receptors. 


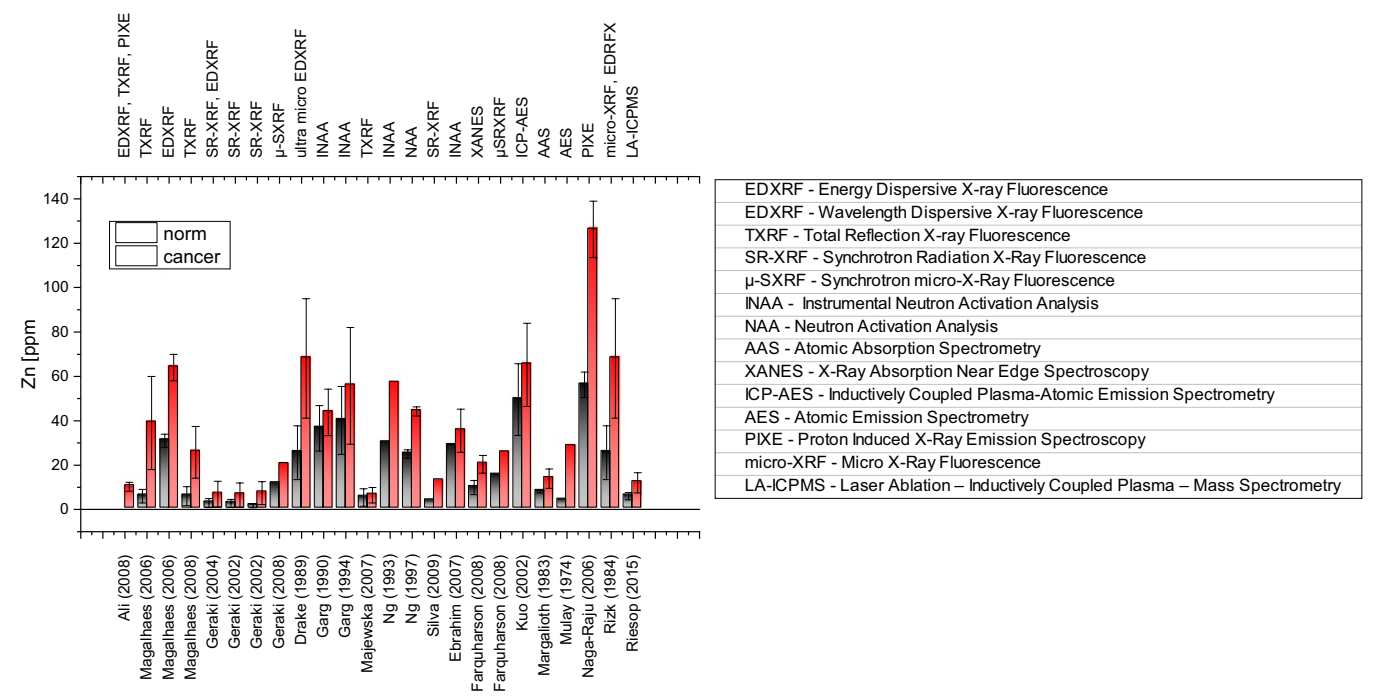

Fig. 1 Different analytical methods for zinc level testing in normal and cancer breast tissue; literature overview. (For numerical values see Appendix Table 2)

\section{Methods}

\section{Tumor tissue samples}

A set of 28 samples of breast cancer tissue was carefully selected and divided into a subset of four "intrinsic" subgroups according to their immunohistochemical receptor profile (steroid- (hormonal-) receptor (HR) positive (HRpos.)/Her2neg. vs. HRneg./Her2pos. vs. HRpos./Her2pos.[triple-positive, TPBC] vs. HRneg./Her2neg.[triplenegative, TNBC]). No additional clinical data was available.

The primary outcome was the determination of zinc concentration and distribution via LA-ICPMS-analysis. The second outcome was the correlation of zinc results with the "intrinsic subtypes" according to immunohistochemical receptor status.

Tissue samples were stored at $-85{ }^{\circ} \mathrm{C}$ in the tissue bank of University Hospital of Essen and were dissected into $10-\mu \mathrm{m}$-thin slides by cryomicrotom. Two subsequent sections were prepared on glass beads. One sample was stained with hematoxylin and eosin (H\&E) and used for microscopic histopathological evaluation. The other section was destined for LA-ICPMS analysis in the Institute for Applied Analytical Chemistry of University of Duisburg-Essen. Storage of tumor samples before processing was at $-80{ }^{\circ} \mathrm{C}$.

\section{Instrumental zinc distribution analysis}

Zinc distribution in the tumor samples was analyzed with LA-ICPMS. The system utilized consisted of a Laser Ablation System UP 213 FP (New Wave Research, ESI Inc., Fremont, CA, USA) and an ICPMS 7500a (Agilent Technologies, Yokogawa, Japan). Transfer of tumor samples to the Institute of Applied Analytical Chemistry was on an aluminum block cooled by liquid nitrogen which was then positioned in a cryoablation chamber held at $-15^{\circ} \mathrm{C}$ and which was purged with helium for elimination of oxygen and water.

Zinc quantification in the tumor samples was performed by application of the method of matrix adapted calibration using a $12.5 \%$ polyacrylamide gel spiked with $\mathrm{Zn}$ standard solution before polymerization; this procedure had already been validated in the course of a PhD thesis and was successfully applied by Riesop [39].

To exclude particulate contaminations, all manipulations were performed within a flow-box.

The laser ablation cell and all related tubings were purged with helium. The LA-ICPMS was then tuned for maximal intensity using NIST SRM 612; important measuring parameters are listed in Table 1.

With a laser spot size of $200 \mu \mathrm{m}$, an ablation line overlapping at $20 \mu \mathrm{m}$, an ablation speed of $50 \mu \mathrm{m} / \mathrm{s}$, and an ICPMS sampling time of $1 \mathrm{~s}$ the final image resolution was $180 \times 50 \mu \mathrm{m}^{2}$.

The elemental contour plots were not smoothed and show element distribution after subtraction of analytical blank. A relatively high sampling inhomogeneity for solid aerosol injection compared to a liquid sampling resulted in a relative standard deviation of approximately $17 \%$ for all measurements.

Cooperation with local pathologists vouched for accuracy of allocation of stromal and cancerous areas in the tumor sample and alignment of section plane in hematoxylin and eosin (H\&E) staining with section plane in zinc-ablation. An example of zinc distribution and quantification in LAICPMS and in histological H\&E staining is shown in Fig. 2. 
Table 1 Applied LA-ICPMS parameters according to Riesop et al. [39]

\begin{tabular}{ll}
\hline Instrumental parameters (unit) & Values \\
\hline Rf power $(\mathrm{W})$ & 1550 \\
Flow rate plasma gas (L/min, Ar) & 15 \\
Flow rate carrier gas (L/min) (Ar) & $1.1-1.2$ \\
Scan modus & Peak hopping \\
Sampling time m/Z (s) & 0.1 \\
Laser spot size $(\mu \mathrm{m})$ & 200 \\
Scan speed $(\mu \mathrm{m} / \mathrm{s})$ & 50 \\
Isotopes monitored & $13 \mathrm{C}, 31 \mathrm{P}, 34 \mathrm{~S}, 54 \mathrm{Fe}, 57 \mathrm{Fe}$, \\
& $63 \mathrm{Cu}, 65 \mathrm{Cu}, 64 \mathrm{Zn}, 66 \mathrm{Zn}$, \\
& $129 \mathrm{Xe}$ \\
Flow rate ablation gas $(\mathrm{L} / \mathrm{min})(\mathrm{He})$ & $1.2-1.3$ \\
Frequency $(\mathrm{Hz})$ & 20 \\
Energy density $\left(\mathrm{mJ} / \mathrm{cm}^{2}\right)$ & 0.8 \\
Laser warm-up time $(\mathrm{s})$ & 5 \\
Washout time $(\mathrm{s})$ & 20 \\
\hline
\end{tabular}

The relevant data of sample classification is shown in the "Appendix" (Table 3).

\section{Results}

LA-ICPMS-guided determination of cancerous vs. noncancerous stromal areas was successful in 26 of 28 samples. Two samples were censored as they were inappropriate for lateral resolution by LA-ICPMS, because the portion of healthy stroma vs. cancerous tissue was too small. Table 3 (see "Appendix") shows numerical results of zinc analysis in the individual tumor sample.

Zinc concentration ranged from 0.8 to 11.4 ppm for stromal and from 3.5 to $19.5 \mathrm{ppm}$ for cancer areas, respectively.
While zinc quantification showed a definite increase in malign areas of the tumor sample, this was paralleled by a mild increase in (benign) adjacent stroma, leading to a relatively constant $\mathrm{Zn}$ (stroma)/Zn(cancer) ratio of $2.9 \pm 1.6$ (Fig. 3).

In line with a pilot-study [39], a trend of zinc level rising with the higher histopathological grade of malignancy (G1-3) was confirmed (Fig. 4). However, statistical significance could not be proved.

A relevant trend of zinc elevation for intrinsic subtypes was observed towards Her2-positive- and towards triplenegative breast cancers. While breast cancers with only positive steroid receptors showed just mild zinc elevations, zinc increased with the expression of the Her2 receptor, thus being higher in HRneg/Her2-positive and even higher in triple-positive (HRpos/Her2pos) breast cancers. Finally, triple-negative (HRneg/Her2neg) breast cancers presented with the highest zinc results (Fig. 5).

Due to size of the sample subsets, a correlation of zinc levels with histological grading according to steroid-receptor-status was only applicable for grade 2 and 3 with a clear trend with highest zinc levels in the HR-negative subgroups (Fig. 6a), but statistical significance could not be proved. Focusing on the steroid-receptor-status only-irrespective of the grade of malignancy - the zinc increase was even more evident in the HR-negative subgroup. It was $68 \%$ higher in HR-negative than in HR-positive breast cancer samples (Fig. 6b).

\section{Discussion}

With regard to the prevalence of zinc in multiple cellular processes and its relevance in cancer this study aimed at these distinct goals:
Fig. 2 "Heatmap" of zinc distribution and quantification by LA-ICPMS (left) and by histological H\&E-staining (right) of parallel sections in a representative tumor sample. $1-$ Malign area, 2-stroma area
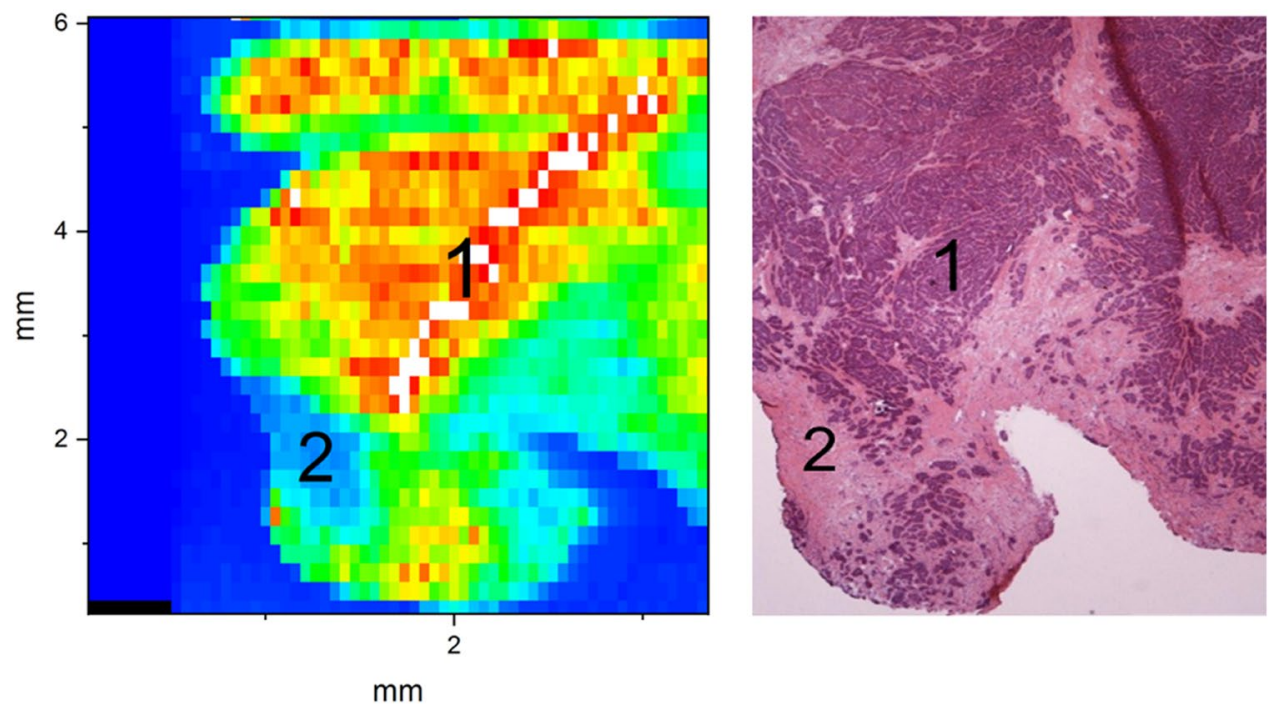

$\mathrm{mm}$ 


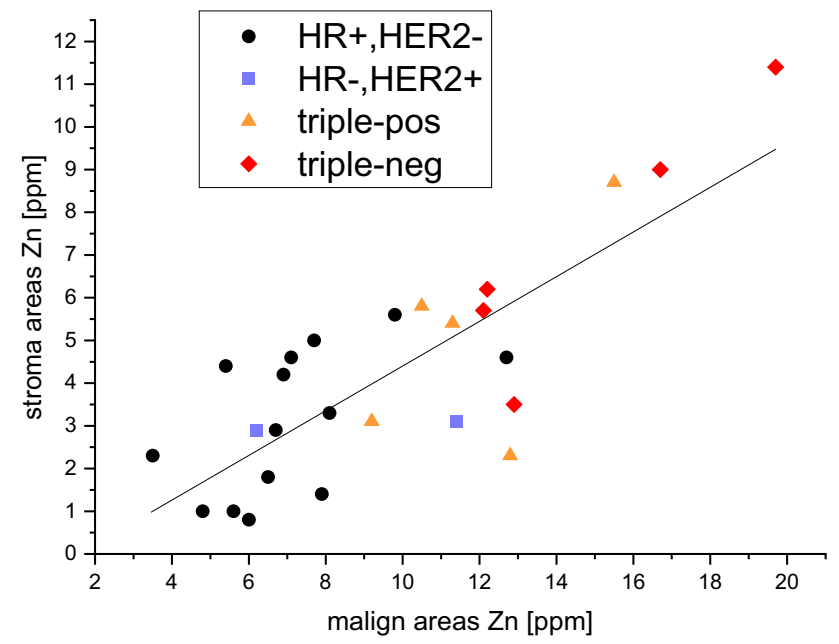

Fig. 3 Comparison of Zinc(stroma)/Zinc(cancer)-ratio of cancer fields vs. (benign) adjacent stroma in different "intrinsic" breast cancer subtypes with a constant ratio over a broad concentration range. (The data set passed the Kolmogorov-Smirnov test for normal distribution.)

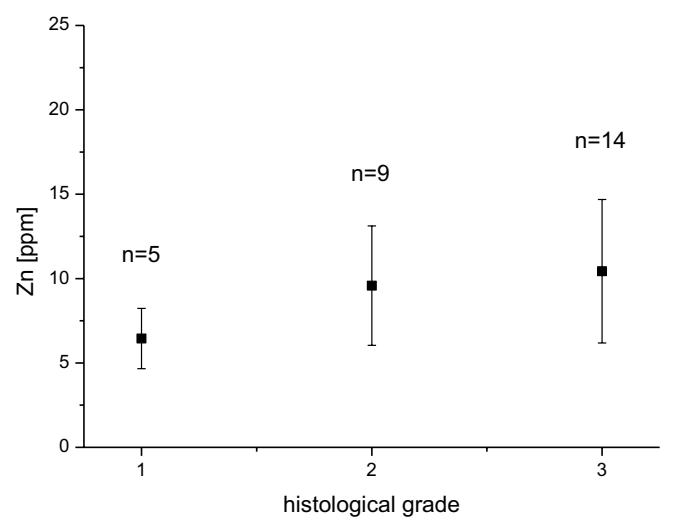

Fig. 4 Error bar plot of zinc level and histopathological grade of malignancy

1. To proof feasibility of LA-ICPMS as a prototype for zinc-analysis in breast cancer; a pilot study demonstrated general applicability of LA-ICPMS for zinc-analysis in breast cancer, but this was only on a very small set of samples [39]. This study was conducted as the confirmatory follow-up study.

2. To relate zinc to breast cancer subtypes according to a distinct pattern of receptor expression.

Status of steroid receptor- and Her2-status expression are the most relevant prognostic and predictive factors routinely determined in histopathology of breast cancer [8, 41, 42]. Genetic profiling allows subgrouping breast cancer into distinct subtypes with subgroup-specific biological behavior [6-8, 42-44].

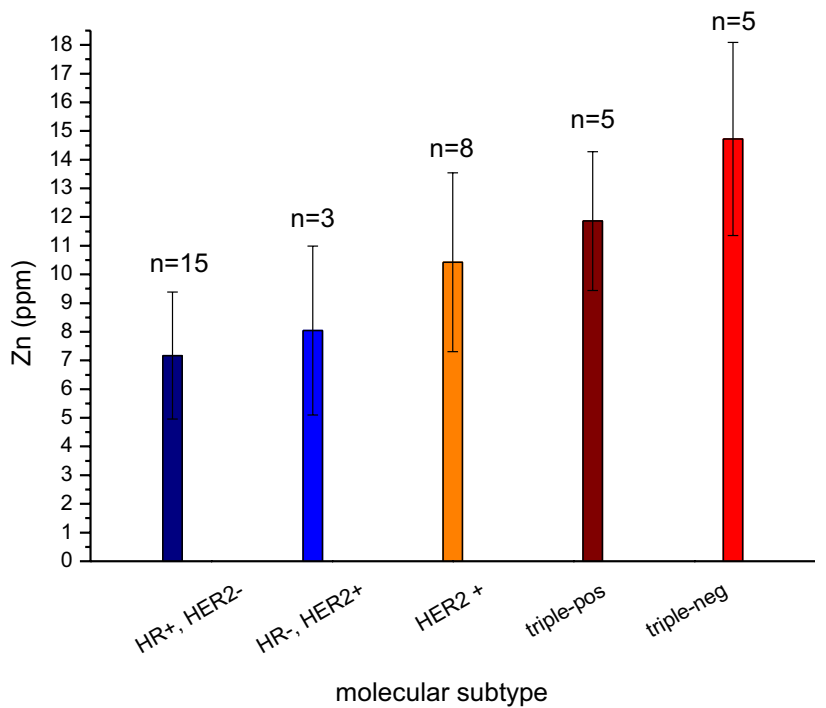

Fig. 5 Error bar plot of zinc-level and intrinsic subtype according to their distinct receptor-profile (according to [40])

Different definitions exist to classify breast cancer into "molecular" or "intrinsic" subtypes. Most commonly distinct patterns of receptor expression and presence of the proliferation marker Ki67 are used for subgrouping. As no clear cut-off-values exist for the definition of Ki67 being "high" or "low", our analysis focused on a simplified classification of molecular subtypes with the focus on receptor expression only and with omission of Ki67 [6,7]. One goal of this study was to relate the results to the expression of the aforementioned receptors.

LA-ICPMS was successfully applied to zinc analysis on a set of 28 breast cancer samples. Zinc was found to be $68 \%$ higher in HRneg than in HRpos samples; this follow-upstudy confirmed most evident zinc elevations in grade 3 (G3) breast cancers.

At the same time zinc was related to the respective breast cancer-subgroup according to the expression of aforementioned receptors with a continuum of zinc-increase from HRpos to Her2pos and finally TPBC (HRpos/Her2pos) and TNBC (HRneg/Her2neg). Unfortunately, due to size of the sample set and as no paired samples where available for analysis, it was impossible to determine if the zinc elevation contributed mainly to the negative steroid-receptor or to the higher grading.

A correlation of the expression of steroid-receptors and histological grade of malignancy was shown by Badowska: Among 231 breast cancer cases, the incidence of positive steroid receptors was highest in the intermediate-risk (G2) subgroup and lowest in the high-risk (G3) subgroup [45].

Results of our own study showed a relation of zinc with steroid receptor profile and with histological grading. No literature exists to answer if zinc concentration according 
Fig. 6 a Error bar plot of zinc and grading within the $\mathrm{HR}+/$ HR- subgroups; b Error bar plot of zinc-level and expression of steroid-receptors

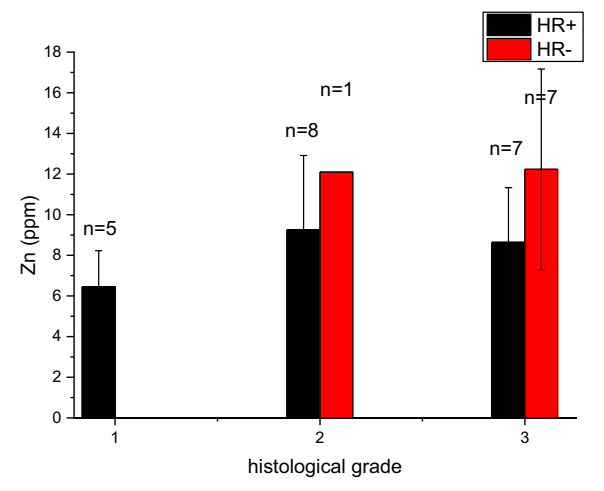

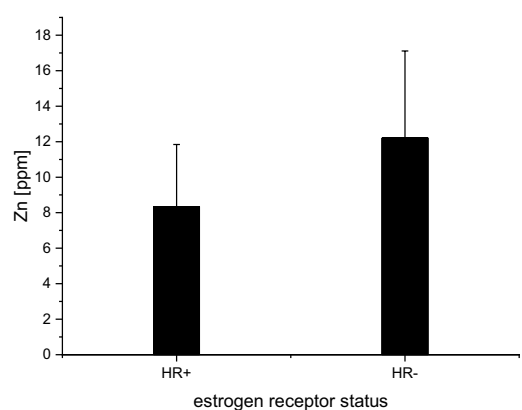

to intrinsic subtypes superimposes that according to histological grading.

Rare studies investigate the role of zinc in the context of different intrinsic breast cancer subtypes: Chandler [22] analyzed the subtype-specific accumulation of zinc in a small study of only six tumor samples with only two different receptor profiles (TPBC, TNBC, non-malignant reference). While using a less precise XRF-microprobe with a lower spatial resolution than in LA-ICPMS, he concludes that intracellular "zinc-management may underlie phenotypic characteristics of breast cancer such as grade, invasiveness, metastatic potential and response to therapy".

Applied analytical research is feasible to trace zinc to its regulatory destination and to visualize zinc-dependent checkpoints for cancer spread. Kim [46] and Chandler [22] used the zinc-responsive fluorophore FluoZin-3 for a correlation of zinc and distinct zinc-transporters in different intrinsic subtypes. They demonstrated different zinc-levels in steroid-positive compared to steroid-negative (basallike) cancers. They hypothesized that the zinc-transporting network may play a key role in distinct subtype-specific biological aggressiveness.

Unlike our own results, Costello [31] observed a downward trend for zinc concentration with higher histological grade, but analysis was based on semi-quantitative zinc determination. Farquharson [33] has shown an overall $60 \%$ higher zinc level in the ER + than in the ER-, however, only grade 1 samples were comprised.

Hypotheses exist with regard to a stepwise development of breast cancer. Zinc appears elevated in breast cancer compared to healthy breast tissue [26, 27]. Nandi found that zinc was 19-fold higher in cancer areas than in the healthy counterpart [47]. In this context, the role of the (healthy?) adjacent stroma as a promoting tumor microenvironment is currently under intensive investigation [48, 49].

Our own study showed a relevant increase of zinc in cancer areas that was paralleled by a mild zinc elevation in adjacent stroma, leading to a relatively constant $\mathrm{Zn}$ (stroma)/ $\mathrm{Zn}$ (cancer) ratio of $2.9 \pm 1.6$. This result is in line with existing literature with values ranging between 1.2 [50] and 6.5 [51].

Hypothetically, stroma-zinc represents the backgroundrisk of breast cancer. In this context, publications discuss the relevance of tumor-stroma as tumor microenvironment promoting cancer growth and initiation of metastasis [52], e.g. via estrogen-receptor-activation [53], via direct or indirect interactions of zinc with the immunosystem [54], via crosstalk between immune cells and cancer cells [55] or via zinc-mediated signaling in growth factor activation $[53,56]$.

In contrast to the aforementioned literature, again only Costello [31] observed an inverse correlation of zinc with cancer fields and adjacent stroma, but this was with an overcome analytical technique and on a small sample size without consideration of receptor expression.

A gross correlation of zinc-content and -distribution with histological grading in breast cancer was already reported in a former pilot study [39]. The confirmatory results of our follow-up-study are with a higher statistical standard deviation, which may be due to the higher number of analyzed samples. Additionally, sample selection criteria for this study were rather based on intrinsic subtypes than on grading.

In our work, zinc levels and intrinsic breast cancer subtypes were related to each other with an upwards trend for "high-risk-cancers" [10,57], while "luminal-like types" (HRpos./Her2neg.) had only mild zinc increases, zinc levels were considerably higher in Her2-positive and finally being highest in triple-negative breast cancers (TNBC). Hypothetically zinc level reflects the continuum from "lowrisk" steroid-positive (luminal) breast cancers (with options for antitumor treatment via the respective target-receptor) via "intermediate-risk" Her2-positive breast cancers (with options for Her2-targeted therapy) to finally autonomous TNBC without any targets for cancer regulation.

Tamoxifen is a selective estrogen-receptor modulator with anti-cancer effects on steroid-receptor-positive breast cancer. Over time of disease a loss of Tamoxifen effect is possible [58]. In this context, Taylor analyzed zinc with regard to developing Tamoxifen resistance via the respective steroid-receptor 
[56]. The zinc transporter ZIP7 was increased in Tamoxifenresistant (TamR) breast cancer cells, resulting in a zinc-wave triggering tumor growth via the activation of growth factorreceptors. Provided that-from a biological standpointTamR-cells are comparable to HRneg-cells, a suchlike zincwave may be the surrogate for our findings of higher zinc levels in HRneg than in HRpos breast cancers.

Accordingly, Lopez and Kelleher [59] showed that overexpression of ZIP6 (LIV-1) zinc-transport-protein is common in ER-positive breast cancer and results in higher intracellular zinc-levels compared to normal breast cells. Conversely, ZIP6-attenuation significantly reduced cellular zinc pools which resulted in decreased apoptosis and finally reduced E-cadherin-expression, which is regarded as a key step in the process of epidermal-mesenchymal transition initiating metastasis.

Analytical research in the context of breast cancer is currently uncommon compared to well-established histopathological analysis. In the context of zinc and breast cancer results of analytical research are often impaired by the use of insufficiently characterized tumor samples not suitable for correlation with histopathological data. Only 1 of 22 publications (see Fig. 1) worked on samples classified according to histopathological grading and clinical stage. A correlation of zinc and estrogen-receptor status was only analyzed by Farquharson [33] and Riesop [39].

Application of LA-ICPMS in clinical routine is limited due to complexity: zinc analysis of a tissue section of approximately $1 \mathrm{~cm}^{2}$ costs several hours, while the test setup and the data evaluation are complex. Finally, it is destructive by vaporization of the analyzed tissue samples, so reproducibility of results is limited.

Yet, analytical research with spatial ablation prepares the ground for advantageous alternative techniques. Cortesi demonstrated feasibility of a non-destructive X-ray-fluorescence for zinc-analysis in screening for prostate cancer [60].

The present study confirms results of a former pilot study with regard to a relation of zinc and histopathological grading in breast cancer. Additionally, this work highlights an association of zinc level with "intrinsic" subtypes in breast cancer according to the expression of steroid- and Her2-receptors. Provided that steroid- and Her2-receptors are of predictive and of prognostic value $[3,61]$ in breast cancer, zinc level may be a surrogate for the inherited risk of the disease.

Still, the core feature of zinc in the context of breast cancer has to be defined.

\section{Conclusion}

There is growing evidence that zinc-homeostasis is a keystone in health and imbalance contributes to cancer initiation and progression.
28 samples of breast cancer tissue were analyzed for zinc content with LA-ICPMS. Results of a pilot study were confirmed and showed elevated zinc levels with increase of the histopathological grade of malignancy.

Relevant zinc increase in cancer areas of the sample were paralleled by mild increases in the adjacent (healthy) stroma, resulting in a relatively constant $\mathrm{Zn}$ (stroma)/Zn (cancer) ratio $(2.9 \pm 1.6)$. This may hint at the surrounding stromal tissue as "tumor-microenvironment" being involved in the course of disease (initiation, progression).

Zinc analysis according to four different "intrinsic" breast cancer subtypes showed a relation of zinc-content with the expression of steroid and Her2 receptors. The connection was closest for "high-risk" cancers, i.e. triple-positive and triplenegative breast cancers. As the latter were mainly of histological grade 3 at the same time, it was not possible to determinate if receptor or grading count more for zinc-elevation.

HRpos samples showed zinc by $68 \%$ higher than HRneg samples. This is in accordance with most of the existing literature.

Some limitations exist in this study: Still, the sample size is small. It was not possible to correlate analytical results to multiple other zinc-associated parameters discussed in literature, i.e. labile zinc ("Zn2+"), zinc transporters or metallothioneins. Standard deviations are relatively high, and it is not possible to determine breast cancer classifications based on zinc content only.

LA-ICPMS for zinc analysis does not seem feasible for clinical routine as it is time consuming and complex with regard to the test setting and the data evaluation. Finally, results cannot be reproduced as vaporization destroys the sample but is essential for the technique. Nonetheless, accuracy of well-established histopathological examinations may benefit from applied analytical research: a next step is the development of similar application studies focusing on analytical techniques feasible for the integration into the clinical routine, e.g. X-ray fluorescence analysis [51, 60, 62], may it be as a supplementary working tool for the histopathologist.

Oncological research in a multidisciplinary setting with basic researchers, clinicians and analytical chemists is new. It may contribute new translational attempts to highlight the core function of zinc in breast cancer and may help to solve the enigma of breast cancer genesis and course of disease.

Author contributions PR: conceptualization, investigation, methodology, data collection, analysis, project administration, writing/editing (original/final draft). AH: literature review, intellectual input, supervision, review. OS: supervision, review. RK: supervision, review. $\mathrm{OH}$ : intellectual input, review. MD: investigation, methodology, data collection, analysis, validation, writing (original/final draft).

Funding Open Access funding enabled and organized by Projekt DEAL. 


\section{Compliance with ethical standards}

Conflict of interest The authors declare that they have no conflict of interest.

Ethical approval The authors confirm that this study was approved by the institutional research ethics committee of University of DuisburgEssen, School of Medicine, and was performed in accordance with ethical standards as laid down in the 1964 Declaration of Helsinki and its later amendments.

Informed consent Informed consent was obtained from all individual participants included in this study.

Open Access This article is licensed under a Creative Commons Attribution 4.0 International License, which permits use, sharing, adaptation, distribution and reproduction in any medium or format, as long as you give appropriate credit to the original author(s) and the source, provide a link to the Creative Commons licence, and indicate if changes were made. The images or other third party material in this article are included in the article's Creative Commons licence, unless indicated otherwise in a credit line to the material. If material is not included in the article's Creative Commons licence and your intended use is not permitted by statutory regulation or exceeds the permitted use, you will need to obtain permission directly from the copyright holder. To view a copy of this licence, visit http://creativecommons .org/licenses/by/4.0/.

\section{Appendix}

See Tables 2 and 3.

Table 2 Zinc (Zn)- level in normal and breast cancer tissue, literature overview

\begin{tabular}{|c|c|c|c|c|c|c|c|c|c|}
\hline Studies & Author & Comment & $n$ & $\begin{array}{l}\text { Mean normal } \\
(\mathrm{ppm} \mathrm{Zn)}\end{array}$ & STD & $n$ & $\begin{array}{l}\text { Mean cancer }(\mathrm{ppm} \\
\mathrm{Zn})\end{array}$ & STD & Analytical method \\
\hline 1 & Ali (2008) [63] & & & & & 24 & 10.2 & 2.0 & $\begin{array}{l}\text { EDXRF, TXRF, } \\
\text { PIXE }\end{array}$ \\
\hline 2 & $\begin{array}{l}\text { Magalhaes et al. } \\
\text { [51] }\end{array}$ & & 1 & 6.0 & 3.0 & 1 & 39.0 & 21.0 & TXRF \\
\hline 3 & $\begin{array}{l}\text { Magalhaes et al. } \\
\text { [51] }\end{array}$ & & 1 & 31.0 & 3.0 & 1 & 64.0 & 6.0 & EDXRF \\
\hline 4 & $\begin{array}{l}\text { Magalhaes et al. } \\
\text { [64] }\end{array}$ & & 6 & 6.0 & 4.3 & 6 & 25.8 & 11.6 & TXRF \\
\hline 5 & Geraki et al. [65] & & & 2.9 & 2.0 & & 6.9 & 5.8 & SR-XRF, EDXRF \\
\hline 6 & Geraki et al. [66] & Paired & 20 & 2.7 & 1.8 & 20 & 6.5 & 5.5 & SR-XRF \\
\hline 7 & Geraki et al. [66] & Independent & 20 & 1.7 & 0.9 & 20 & 7.4 & 5.2 & SR-XRF \\
\hline 8 & Geraki et al. [67] & Spacial res & 1 & 10.9 & 5.6 & 1 & 23.9 & 8.8 & $\mu$-SXRF \\
\hline 9 & Drake et al. [68] & & 26 & 25.6 & 12.1 & 26 & 68.1 & 26.9 & ultra micro-EDXRF \\
\hline 10 & Garg et al. [69] & & 4 & 36.6 & 10.2 & 4 & 43.8 & 10.5 & INAA \\
\hline 11 & Garg et al. [70] & & 30 & 40.1 & 15.3 & 30 & 55.8 & 26.3 & INAA \\
\hline 12 & $\begin{array}{l}\text { Majewska et al. } \\
\text { [50] }\end{array}$ & & 68 & 5.4 & 3.9 & 26 & 6.4 & 3.4 & TXRF \\
\hline 13 & $\mathrm{Ng}$ et al. [71] & Median, paired & 15 & $30.0(14-42)$ & & 15 & $57.0(28-113)$ & & INAA \\
\hline 14 & $\mathrm{Ng}$ et al. [72] & & 46 & 25.0 & 1.9 & 46 & 44.2 & 2.1 & NAA \\
\hline 15 & Silva et al. [73] & Paired & 26 & 3.8 & & 26 & 12.9 & & SR-XRF \\
\hline 16 & Ebrahim et al. [74] & Dry & & 28.8 & & & 35.5 & 9.8 & INAA \\
\hline 17 & $\begin{array}{l}\text { Farquharson et al. } \\
\text { [75] }\end{array}$ & & 9 & 9.9 & 3.2 & 9 & 20.4 & 4.0 & XANES \\
\hline 18 & $\begin{array}{l}\text { Farquharson et al. } \\
\text { [75] }\end{array}$ & Spacial res & 2 & 15.4 & & 2 & 25.5 & & $\mu \mathrm{SRXRF}$ \\
\hline 19 & Kuo et al. [76] & Wet paired & 25 & 49.6 & 16.1 & 25 & 65.2 & 18.8 & ICP-AES \\
\hline 20 & $\begin{array}{l}\text { Margalioth et al. } \\
\text { [26] }\end{array}$ & Wet & 4 & 8.1 & 0.6 & 8 & 13.9 & 4.4 & AAS \\
\hline 21 & Mulay et al. [25] & Dry & 8 & 4.0 & $(1.1-9.3)$ & 8 & 28.3 & $(8.5-84)$ & AES \\
\hline 22 & $\begin{array}{l}\text { Naga-Raju et al. } \\
\text { [77] }\end{array}$ & Dry & 18 & 56.2 & 5.8 & 18 & 126.2 & 12.7 & PIXE \\
\hline 23 & Rizk et al. [78] & Dry & 22 & 25.6 & 12.1 & 22 & 68.1 & 26.9 & micro-XRF EDRFX \\
\hline 24 & Riesop et al. [39] & $\begin{array}{l}\text { Wet tissue, special } \\
\text { res }\end{array}$ & 9 & 6.0 & 1.6 & 9 & 12.0 & 4.6 & LA-ICPMS \\
\hline
\end{tabular}


Table 3 Zinc concentrations of "cancer fields" and of "adjacent stroma" in 28 breast cancer tissue sections

\begin{tabular}{|c|c|c|c|c|c|c|}
\hline & Sample name & Grade & Subgroup & $\begin{array}{l}\text { Proportion } \\
\text { of cancer } \\
{[\%]}\end{array}$ & $\begin{array}{l}\text { Zn-concentration } \\
\text { "cancer fields" } \\
\text { [ppm] }\end{array}$ & $\begin{array}{l}\text { Zn-concentration } \\
\text { "adjacent stroma" } \\
{[\mathrm{ppm}]}\end{array}$ \\
\hline 1 & E171-07 & 1 & HRposHER2neg & 20 & $6.0 \pm 1.2$ & $0.8 \pm 0.2$ \\
\hline 2 & E30921-10 & 1 & HRposHER2neg & 30 & $7.7 \pm 1.6$ & $5.0 \pm 0.6$ \\
\hline 3 & E15529-9 & 1 & HRposHER2neg & 40 & $3.5 \pm 0.4$ & $2.3 \pm 0.4$ \\
\hline 4 & E16137-09 & 1 & HRposHER2neg & 40 & $7.9 \pm 2.6$ & $1.4 \pm 0.2$ \\
\hline 5 & E16883-08 & 1 & HRposHER2neg & 80 & $7.1 \pm 0.6$ & $4.6 \pm 0.6$ \\
\hline 6 & $122-536 \mathrm{I}$ & 2 & triple-neg & 60 & $12.1 \pm 3.2$ & $5.7 \pm 1.2$ \\
\hline 7 & 226-999III & 2 & HRposHER2pos & 60 & $11.3 \pm 0.8$ & $5.4 \pm 0.7$ \\
\hline 8 & 193-902IV & 2 & HRposHER2pos & 90 & $15.5 \pm 1.4$ & $8.7 \pm 0.7$ \\
\hline 9 & 171-357I & 2 & HRposHER2pos & 80 & $12.8 \pm 1$ & $2.3 \pm 0.4$ \\
\hline 10 & E17591-07 & 2 & HRposHER2neg & 50 & $8.1 \pm 0.8$ & $3.3 \pm 0.6$ \\
\hline 11 & E28891-06 & 2 & HRposHER2neg & 75 & $5.4 \pm 0.6$ & $4.4 \pm 0.6$ \\
\hline 12 & E30167-08 & 2 & HRposHER2neg & 90 & $8.9 \pm 1.0$ & - \\
\hline 13 & E13244-8 & 2 & HRposHER2neg & 40 & $6.5 \pm 1.0$ & $1.8 \pm 0.4$ \\
\hline 14 & E25812-07 & 2 & HRposHER2neg & 85 & $5.6 \pm 0.6$ & $1 \pm 0.2$ \\
\hline 15 & 185-800III & 3 & HRposHER2pos & 70 & $9.2 \pm 0.8$ & $3.1 \pm 1.0$ \\
\hline 16 & 187-827III & 3 & HRposHER2pos & 90 & $10.5 \pm 1$ & $5.8 \pm 1.3$ \\
\hline 17 & E16996-8 & 3 & HRnegHER2pos & 40 & $11.4 \pm 1.5$ & $3.1 \pm 0.6$ \\
\hline 18 & E16452-10 & 3 & HRnegHER2pos & 95 & $6.5 \pm 0.6$ & - \\
\hline 19 & E15334-8 & 3 & HRnegHER2pos & 25 & $6.2 \pm 0.6$ & $2.9 \pm 0.2$ \\
\hline 20 & E30802-07 & 3 & HRposHER2neg & 75 & $6.7 \pm 1.0$ & $2.9 \pm 0.4$ \\
\hline 21 & E6408-08 & 3 & HRposHER2neg & 90 & $9.8 \pm 1.0$ & $5.6 \pm 1.0$ \\
\hline 22 & E2141-07 & 3 & HRposHER2neg & 90 & $6.9 \pm 0.6$ & $4.2 \pm 0.8$ \\
\hline 23 & E25767-06 & 3 & HRposHER2neg & 10 & $4.8 \pm 1.2$ & $1.0 \pm 0.2$ \\
\hline 24 & E5809-08 & 3 & HRposHER2neg & 50 & $12.7 \pm 1.8$ & $4.6 \pm 0.8$ \\
\hline 25 & $17-1344 \mathrm{~V}$ & 3 & Triple-neg & 95 & $12.9 \pm 1.3$ & $3.5 \pm 1.3$ \\
\hline 26 & 176-734III & 3 & Triple-neg & 90 & $12.2 \pm 2.3$ & $6.2 \pm 1.0$ \\
\hline 27 & $322-124 I V$ & 3 & Triple-neg & 90 & $16.7 \pm 2.6$ & $9 \pm 1.9$ \\
\hline 28 & 112-475II & 3 & Triple-neg & 70 & $19.7 \pm 2.7$ & $11.4 \pm 2$ \\
\hline
\end{tabular}

\section{References}

1. American Cancer Society (2019) Breast cancer facts and figures 2019-2020. https://www.cancer.org/content/dam/cance r-org/research/cancer-facts-and-statistics/breast-cancer-facts -and-figures/breast-cancer-facts-and-figures-2019-2020.pdf

2. Bethesda, MD: National Cancer Institute (2020) PDQ ${ }^{\circledR}$ Cancer Genetics Editorial Board. PDQ Genetics of Breast and Gynecologic Cancers. https://www.cancer.gov/types/breast/hp/ breast-ovarian-genetics-pdq. Accessed 20 Aug 2020. [PMID: 26389210]

3. Yu F, Quan F, Xu J et al (2019) Breast cancer prognosis signature: linking risk stratification to disease subtypes. Brief Bioinf 20:2130-2140. https://doi.org/10.1093/bib/bby073

4. Kurian AW, Antoniou AC, Domchek SM (2016) Refining breast cancer risk stratification: additional genes, additional information. Am Soc Clin Oncol Educ Book 35:44-56. https://doi. org/10.1200/EDBK_158817

5. Yersal O, Barutca S (2014) Biological subtypes of breast cancer: Prognostic and therapeutic implications. World J Clin Oncol 5:412-424. https://doi.org/10.5306/wjco.v5.i3.412
6. Perou CM, Sørlie T, Eisen MB et al (2000) Molecular portraits of human breast tumours. Nature 406:747-752. https://doi. org/10.1038/35021093

7. Sørlie T, Perou CM, Tibshirani R et al (2001) Gene expression patterns of breast carcinomas distinguish tumor subclasses with clinical implications. Proc Natl Acad Sci USA 98:10869-10874. https://doi.org/10.1073/pnas.191367098

8. Kondov B, Milenkovikj Z, Kondov G et al (2018) Presentation of the molecular subtypes of breast cancer detected by immunohistochemistry in surgically treated patients. Open Access Maced J Med Sci 6:961-967. https://doi.org/10.3889/oamjms.2018.231

9. van't Veer LJ, Dai H, van de Vijver MJ et al (2002) Gene expression profiling predicts clinical outcome of breast cancer. Nature 415:530-536. https://doi.org/10.1038/415530a

10. Fallahpour S, Navaneelan T, De P et al (2017) Breast cancer survival by molecular subtype: a population-based analysis of cancer registry data. CMAJ Open 5:E734-E739. https://doi.org/10.9778/ cmajo. 20170030

11. Slamon DJ, Clark GM, Wong SG et al (1987) Human breast cancer: correlation of relapse and survival with amplification of the HER-2/neu oncogene. Science 235:177-182. https://doi. org/10.1126/science.3798106 
12. Slamon DJ, Leyland-Jones B, Shak S et al (2001) Use of chemotherapy plus a monoclonal antibody against HER2 for metastatic breast cancer that overexpresses Her2. N Engl J Med 344:783792. https://doi.org/10.1056/NEJM200103153441101

13. Sparano JA, Gray RJ, Della Makower F et al (2018) Adjuvant chemotherapy guided by a 21-gene expression assay in breast cancer. N Engl J Med 379:111-121. https://doi.org/10.1056/NEJMo a1804710

14. Cardoso F, van't Veer LJ, Bogaerts J et al (2016) 70-gene signature as an aid to treatment decisions in early-stage breast cancer. N Engl J Med 375:717-729. https://doi.org/10.1056/NEJMoa1602 253

15. Liu MC, Pitcher BN, Mardis ER et al (2016) PAM50 gene signatures and breast cancer prognosis with adjuvant anthracyclineand taxane-based chemotherapy: correlative analysis of C9741 (Alliance). NPJ Breast Cancer. https://doi.org/10.1038/npjbcancer .2015 .23

16. Prasad AS, Beck FWJ, Snell DC et al (2009) Zinc in cancer prevention. Nutr Cancer 61:879-887. https://doi.org/10.1080/01635 580903285122

17. Franklin RB, Costello LC (2009) The important role of the apoptotic effects of zinc in the development of cancers. J Cell Biochem 106:750-757. https://doi.org/10.1002/jcb.22049

18. Maret W (2017) Zinc in cellular regulation: the nature and significance of "zinc signals". Int J Mol Sci. https://doi.org/10.3390/ ijms 18112285

19. Taylor KM, Hiscox S, Nicholson RI et al (2012) Protein kinase CK2 triggers cytosolic zinc signaling pathways by phosphorylation of zinc channel ZIP7. Sci Signal 5:ra11. https://doi. org/10.1126/scisignal.2002585

20. Takatani-Nakase $\mathrm{T}$ (2018) Zinc transporters and the progression of breast cancers. Biol Pharm Bull 41:1517-1522. https://doi. org/10.1248/bpb.b18-00086

21. Grattan BJ, Freake HC (2012) Zinc and cancer: implications for LIV-1 in breast cancer. Nutrients 4:648-675. https://doi. org/10.3390/nu4070648

22. Chandler P, Kochupurakkal BS, Alam S et al (2016) Subtypespecific accumulation of intracellular zinc pools is associated with the malignant phenotype in breast cancer. Mol Cancer 15:2. https ://doi.org/10.1186/s12943-015-0486-y

23. Skrajnowska D, Bobrowska-Korczak B (2019) Role of zinc in immune system and anti-cancer defense mechanisms. Nutrients. https://doi.org/10.3390/nu11102273

24. Woo W, Xu Z (2002) Body zinc distribution profile during $N$-methyl- $N$-nitrosourea-induced mammary tumorigenesis in rats at various levels of dietary zinc intake. Biol Trace Elem Res 87:157-169. https://doi.org/10.1385/BTER:87:1-3:157

25. Mulay IL, Roy R, Knox BE et al (1971) Trace-metal analysis of cancerous and noncancerous human tissues. J Natl Cancer Inst 47:1-13

26. Margalioth EJ, Schenker JG, Chevion M (1983) Copper and zinc levels in normal and malignant tissues. Cancer 52:868-872. https ://doi.org/10.1002/1097-0142(19830901)52:5<868:AID-CNCR2 $820520521>3.0 . \mathrm{CO} ; 2-\mathrm{K}$

27. Santoliquido PM, Southwick HW, Olwin JH (1976) Trace metal levels in cancer of the breast. Surg Gynecol Obstet 142(1):65-70

28. Jin R, Bay B, Tan P et al (1999) Metallothionein expression and zinc levels in invasive ductal breast carcinoma. Oncol Rep 6:871875. https://doi.org/10.3892/or.6.4.871

29. Lee R, Woo W, Wu B et al (2003) Zinc accumulation in $N$-methyl$\mathrm{N}$-nitrosourea-induced rat mammary tumors is accompanied by an altered expression of ZnT-1 and metallothionein. Exp Biol Med (Maywood) 228:689-696

30. Gumulec J, Masarik M, Adam V, Eckschlager T, Provaznik I et al (2014) Serum and tissue zinc in epithelial malignancies: a meta-analysis. PLoS ONE 9(6):e99790. https://doi.org/10.1371/ journal.pone.0099790

31. Costello LC, Zou J, Franklin RB (2016) In situ clinical evidence that zinc levels are decreased in breast invasive ductal carcinoma. Cancer Causes Control 27:729-735. https://doi.org/10.1007/s1055 2-016-0746-1

32. Cui Y, Vogt S, Olson N et al (2007) Levels of zinc, selenium, calcium, and iron in benign breast tissue and risk of subsequent breast cancer. Cancer Epidemiol Biomarkers Prev 16:1682-1685. https://doi.org/10.1158/1055-9965.EPI-07-0187

33. Farquharson MJ, Al-Ebraheem A, Geraki K et al (2009) Zinc presence in invasive ductal carcinoma of the breast and its correlation with oestrogen receptor status. Phys Med Biol 54:4213-4223. https://doi.org/10.1088/0031-9155/54/13/016

34. Taylor KM, Morgan HE, Smart K et al (2007) The emerging role of the LIV-1 subfamily of zinc transporters in breast cancer. Mol Med 13:396-406. https://doi.org/10.2119/2007-00040.Taylor

35. Ziliotto S, Gee JMW, Ellis IO et al (2019) Activated zinc transporter ZIP7 as an indicator of anti-hormone resistance in breast cancer. Metallomics 11:1579-1592. https://doi.org/10.1039/c9mt0 0136k

36. Liguori PF, Valentini A, Palma M et al (2010) Non-classical anticancer agents: synthesis and biological evaluation of zinc(II) heteroleptic complexes. Dalton Trans 39:4205-4212. https://doi. org/10.1039/b922101h

37. Chen Y, Lai B, Zhang Z et al (2017) The effect of metalloprotein inhibitors on cellular metal ion content and distribution. Metallomics 9:250-257. https://doi.org/10.1039/c6mt00267f

38. Rodríguez MR, Del Plá J, Balsa LM et al (2019) Cu(II) and Zn(II) complexes with a poly-functional ligand derived from o-vanillin and thiophene. Crystal structure, physicochemical properties, theoretical studies and cytotoxicity assays against human breast cancer cells. New J Chem 43:7120-7129. https://doi.org/10.1039/ C8NJ06274A

39. Riesop D, Hirner AV, Rusch P et al (2015) Zinc distribution within breast cancer tissue: a possible marker for histological grading? J Cancer Res Clin Oncol 141:1321-1331. https://doi.org/10.1007/ s00432-015-1932-3

40. Nakshatri H, Srour EF, Badve S (2009) Breast cancer stem cells and intrinsic subtypes: controversies rage on. Curr Stem Cell Res Ther 4:50-60. https://doi.org/10.2174/157488809787169110

41. Bennis S, Abbass F, Akasbi Y et al (2012) Prevalence of molecular subtypes and prognosis of invasive breast cancer in north-east of Morocco: retrospective study. BMC Res Notes 5:436. https:// doi.org/10.1186/1756-0500-5-436

42. Goldhirsch A, Winer EP, Coates AS et al (2013) Personalizing the treatment of women with early breast cancer: highlights of the St Gallen international expert consensus on the primary therapy of early breast cancer 2013. Ann Oncol 24:2206-2223. https://doi. org/10.1093/annonc/mdt303

43. Fragomeni SM, Sciallis A, Jeruss JS (2018) Molecular subtypes and local-regional control of breast cancer. Surg Oncol Clin N Am 27:95-120. https://doi.org/10.1016/j.soc.2017.08.005

44. Zhou J, Yan Y, Guo L et al (2014) Distinct outcomes in patients with different molecular subtypes of inflammatory breast cancer. Saudi Med J 35:1324-1330

45. Badowska-Kozakiewicz AM, Patera J, Sobol M et al (2015) The role of oestrogen and progesterone receptors in breast cancer immunohistochemical evaluation of oestrogen and progesterone receptor expression in invasive breast cancer in women. Contemp Oncol (Pozn) 19:220-225. https://doi.org/10.5114/wo.2015.51826

46. Kim HG, Kim JY, Han EH et al (2011) Metallothionein-2A overexpression increases the expression of matrix metalloproteinase- 9 and invasion of breast cancer cells. FEBS Lett 585:421-428. https ://doi.org/10.1016/j.febslet.2010.12.030 
47. Nandi S, Guzman RC, Yang J (1995) Hormones and mammary carcinogenesis in mice, rats, and humans: a unifying hypothesis. Proc Natl Acad Sci USA 92:3650-3657. https://doi.org/10.1073/ pnas.92.9.3650

48. Bussard KM, Mutkus L, Stumpf K et al (2016) Tumor-associated stromal cells as key contributors to the tumor microenvironment. Breast Cancer Res. https://doi.org/10.1186/s13058-016-0740-2

49. Guo S, Deng C-X (2018) Effect of stromal cells in tumor microenvironment on metastasis initiation. Int J Biol Sci 14:2083-2093. https://doi.org/10.7150/ijbs.25720

50. Majewska U, Banaś D, Braziewicz J et al (2007) Trace element concentration distributions in breast, lung and colon tissues. Phys Med Biol 52:3895-3911. https://doi. org/10.1088/0031-9155/52/13/016

51. Magalhães T, von Bohlen A, Carvalho ML et al (2006) Trace elements in human cancerous and healthy tissues from the same individual: a comparative study by TXRF and EDXRF. Spectrochim Acta Part B 61:1185-1193. https://doi.org/10.1016/j. sab.2006.06.002

52. Yuan Y, Jiang Y-C, Sun C-K et al (2016) Role of the tumor microenvironment in tumor progression and the clinical applications (Review). Oncol Rep 35:2499-2515. https://doi.org/10.3892/ or.2016.4660

53. Segovia-Mendoza M, Morales-Montor J (2019) Immune tumor microenvironment in breast cancer and the participation of estrogens and its receptors into cancer physiopathology. Front Immunol 10:348. https://doi.org/10.3389/fimmu.2019.00348

54. John E, Laskow TC, Buchser WJ et al (2010) Zinc in innate and adaptive tumor immunity. J Transl Med 8:118. https://doi. org/10.1186/1479-5876-8-118

55. Nagarajan D, McArdle SEB (2018) Immune landscape of breast cancers. Biomedicines. https://doi.org/10.3390/biomedicines601 0020

56. Taylor KM, Vichova P, Jordan N et al (2008) ZIP7-mediated intracellular zinc transport contributes to aberrant growth factor signaling in antihormone-resistant breast cancer cells. Endocrinology 149:4912-4920. https://doi.org/10.1210/en.2008-0351

57. Prakash C, Gunda A, Attuluri AK, Madhav L, Ramkumar C, Basavaraj C, Naidu N, Bakre MM (2018) Risk stratification in earlystage estrogen receptor+/Her2-breast cancer patients: comparative analysis of cost-effective methods. J Curr Oncol 1:5-15. https:// doi.org/10.4103/jco.jco_12_17

58. Rani A, Stebbing J, Giamas G et al (2019) Endocrine resistance in hormone receptor positive breast cancer-from mechanism to therapy. Front Endocrinol (Lausanne) 10:245. https://doi.org/10.3389/ fendo.2019.00245

59. Lopez V, Kelleher SL (2010) Zip6-attenuation promotes epithelial-to-mesenchymal transition in ductal breast tumor (T47D) cells. Exp Cell Res 316:366-375. https://doi.org/10.1016/j.yexcr .2009.10.011

60. Cortesi M, Fridman E, Volkov A et al (2010) New prospective for non-invasive detection, grading, size evaluation, and tumor location of prostate cancer. Prostate 70:1701-1708. https://doi. org/10.1002/pros.21205

61. Vieira AF, Schmitt F (2018) An update on breast cancer multigene prognostic tests-emergent clinical biomarkers. Front Med (Lausanne) 5:248. https://doi.org/10.3389/fmed.2018.00248

62. Geraki K, Farquharson MJ, Bradley DA (2004) X-ray fluorescence and energy dispersive $\mathrm{x}$-ray diffraction for the quantification of elemental concentrations in breast tissue. Phys Med Biol 49:99-110. https://doi.org/10.1088/0031-9155/49/1/007

63. Ali QM (2008) Trace metals in scalp hair, plasma and tissues as an index of cancer. Dissertation, Quaid-i-Azam University, Islamabad. Department of Biochemistry. http://prr.hec.gov.pk/jspui/bitst ream/123456789/3188/1/2468.pdf
64. Magalhães T, Becker M, Carvalho ML et al (2008) Study of Br, $\mathrm{Zn}, \mathrm{Cu}$ and $\mathrm{Fe}$ concentrations in healthy and cancer breast tissues by TXRF. Spectrochim Acta Part B 63:1473-1479. https://doi. org/10.1016/j.sab.2008.10.014

65. Geraki K, Farquharson MJ, Bradley DA et al (2004) A synchrotron XRF study on trace elements and potassium in breast tissue. Nucl Instrum Methods Phys Res Sect B 213:564-568. https://doi. org/10.1016/S0168-583X(03)01672-0

66. Geraki K, Farquharson MJ, Bradley DA (2002) Concentrations of $\mathrm{Fe}, \mathrm{Cu}$ and $\mathrm{Zn}$ in breast tissue: a synchrotron XRF study. Phys Med Biol 47:2327-2339. https://doi.org/10.1088/0031-9155/47/13/310

67. Geraki K, Farquharson MJ, Bradley DA et al (2008) The localisation of biologically important metals in soft and calcified tissues using a synchrotron $\mathrm{x}$-ray fluorescence technique. X-Ray Spectrom 37:12-20. https://doi.org/10.1002/xrs.999

68. Drake II EN, Sky-Peck HH (1989) Discriminant analysis of trace element distribution in nomal and malignant human tissues. Cancer Res 49(15):4210-4215

69. Garg AN, Weginwar RG, Sagdeo V (1990) Minor and trace elemental contents of cancerous breast tissue measured by instrumental and radiochemical neutron activation analysis. Biol Trace Elem Res 26-27:485-496. https://doi.org/10.1007/BF02992704

70. Garg AN, Singh V, Weginwar RG et al (1994) An elemental correlation study in cancerous and normal breast tissue with successive clinical stages by neutron activation analysis. Biol Trace Elem Res 46:185-201. https://doi.org/10.1007/BF02789296

71. Ng K-H, Bradley DA, Looi L-M et al (1993) Differentiation of elemental composition of normal and malignant breast tissue by instrumental neutron activation analysis. Appl Radiat Isot 44:511516. https://doi.org/10.1016/0969-8043(93)90162-4

72. Ng KH, Bradley DA, Looi LM (1997) Elevated trace element concentrations in malignant breast tissues. Br J Radiol 70:375-382. https://doi.org/10.1259/bjr.70.832.9166074

73. Silva MP, Tomal A, Pérez CA et al (2009) Determination of Ca, $\mathrm{Fe}, \mathrm{Cu}$ and $\mathrm{Zn}$ and their correlations in breast cancer and normal adjacent tissues. X-Ray Spectrom 38:103-111. https://doi. org/10.1002/xrs. 1126

74. Ebrahim AM, Eltayeb MAH, Shaat MK et al (2007) Study of selected trace elements in cancerous and non-cancerous human breast tissues from Sudanese subjects using instrumental neutron activation analysis. Sci Total Environ 383:52-58. https://doi. org/10.1016/j.scitotenv.2007.04.047

75. Farquharson MJ, Al-Ebraheem A, Falkenberg G et al (2008) The distribution of trace elements $\mathrm{Ca}, \mathrm{Fe}, \mathrm{Cu}$ and $\mathrm{Zn}$ and the determination of copper oxidation state in breast tumour tissue using muSRXRF and muXANES. Phys Med Biol 53:3023-3037. https ://doi.org/10.1088/0031-9155/53/11/018

76. Kuo HW, Chen SF, Wu CC et al (2002) Serum and tissue trace elements in patients with breast cancer in Taiwan. Biol Trace Elem Res 89:1-12. https://doi.org/10.1385/BTER:89:1:1

77. Raju GN, Sarita P, Kumar MR et al (2006) Trace elemental correlation study in malignant and normal breast tissue by PIXE technique. Nucl Instrum Methods Phys Res Sect B 247:361-367. https://doi.org/10.1016/j.nimb.2006.02.007

78. Rizk SL, Sky-Peck HH (1984) Comparison between concentrations of trace elements in normal and neoplastic human breast tissue. Can Res 44:5390-5394

Publisher's Note Springer Nature remains neutral with regard to jurisdictional claims in published maps and institutional affiliations. 